\title{
Análise econômica da interação entre a infraestrutura da saúde pública e privada no Brasil $^{1}$
}

\author{
Marislei Nishijima ${ }^{2}$ \\ Denise Cavallini Cyrillo ${ }^{3}$ \\ Geraldo Biasoto Junior ${ }^{4}$
}

\section{Resumo}

Este artigo analisa de que forma a interação entre o setor público e privado de saúde da economia brasileira, avaliando como a sua estrutura produtiva, aliada ao aparato legal referente ao período anterior à regulação da Agência Nacional de Saúde Suplementar, pode ter causado um impacto negativo sobre o acesso dos brasileiros de baixa renda aos bens públicos de saúde. Para dar suporte aos argumentos apresentados, foram utilizados os microdados do suplemento saúde da PNAD de 1998, analisados por meio de modelos logit e probit tendo em vista o caráter qualitativo da variável dependente. Os resultados sugerem evidências favoráveis à hipótese proposta.

Palavras-chave: Assistência médica; Saúde pública; Saúde privada; Seguro de saúde; ANS.

\section{Abstract \\ Economic analysis of the Brazilian public and private health infrastructure}

This article analyses how the last Brazilian Constitution - which regulates the universal rights of public health care - has negatively impacted the distribution of health care in terms of the access that Brazilians with lower incomes have to public health care. The specific way that the public and private sectors of health care functions has caused this to happen. This phenomenon was indirectly tested using supplementary health economics survey data, together with a traditional household survey, the "Pesquisa Nacional de Amostra por Domicílio" (PNAD), from 1998. Logit and probit models were used to analyze the data, and the results supported the proposed hypothesis.

Key words: Medical care; Public health; Private health; Health insurance; ANS.

JEL I11, I18, D12

\section{Introdução}

Este trabalho teve por objetivo investigar uma situação particular do sistema de saúde brasileiro que, supostamente, perdurou até o início da regulação do setor privado de saúde pela Agência Nacional de Saúde Suplementar (ANS) em

(1) Trabalho recebido em setembro de 2008 e aprovado em setembro de 2009.

(2) Professora Associada da Escola de Artes, Ciências e Humanidades da Universidade de São Paulo (EACH-USP), São Paulo, SP, Brasil. E-mail: marislei@usp.br.

(3) Professora Associada da Faculdade de Economia, Administração e Contabilidade da Universidade de São Paulo (FEA-USP), São Paulo, SP, Brasil. E-mail: dccyrill@ usp.br.

(4) Professor Doutor do Instituto de Economia da Universidade Estadual de São Paulo (IE-Unicamp), Campinas, SP, Brasil. E-mail: gbiasoto@uol.com.br. 
2000. ${ }^{5}$ A hipótese investigada, de que os consumidores de planos de saúde privados tiveram mais acesso aos bens de assistência médica com internações ofertados pelo setor público do que os não consumidores (gerando uma piora de bem estar para a sociedade), foi inspirada nos estudos realizados para a ANS, financiados pelo Banco Interamericano de Desenvolvimento, e para a Organização Pan-americana de Saúde (OPAS). ${ }^{6}$

Em linhas gerais, o sistema brasileiro de saúde é um sistema misto, onde convivem um sistema público e um privado de saúde. O Sistema Único de Saúde (SUS), o sistema público de assistência à saúde, foi definido pela Constituição de $1988^{7}$ e instituído pela Lei 8.080 de 19 de setembro de 1990, com a função primordial de promover a saúde pública no país baseado em três princípios: universalidade, integralidade e descentralização. ${ }^{8}$ O SUS, entretanto, se caracteriza por possuir uma oferta insuficiente de bens e serviços de saúde para a população, com indicadores inferiores aos recomendados pela Organização Mundial da Saúde na maior parte das regiões do país (Farias; Melamed, 2003). É importante frisar que neste artigo, conforme definição de Arrow (1963), o termo bens e serviços de saúde é usado como sinônimo de bens e serviços de assistência médica (medical care).

A oferta insuficiente de bens públicos de assistência médica impõe um tempo positivo de espera pelos tratamentos, principalmente por aqueles que não se configuram como uma emergência, ${ }^{9}$ reduzindo a resolutividade do sistema, e consequentemente limitando o seu acesso. Vale notar que o tempo de espera para o acesso aos bens públicos de saúde se configura como um problema quando é maior do que o tempo de espera socialmente desejado, conforme será visto na próxima seção.

O SUS nasceu como um sistema universal e "único" na Constituição de 1988; no entanto, na própria constituição há espaço para o setor privado, na forma de um sistema suplementar (Almeida, 1998). Desse modo, não surpreende o fato de que o segmento privado possui grande magnitude - tendo sido responsável por $59,2 \%$ dos gastos com saúde no país em 2000, operando principalmente na forma

(5) Embora várias informações veiculadas no país insistam que o problema ainda permanece. Ver http://www.cns.org.br/links/menup/noticiadosetor/clipping/2006/09/clipping 1209.htm.

(6) Estudos realizados por profissionais da Universidade Estadual de Campinas e da Universidade Federal do Rio de Janeiro: convênio ATN/MT-6982-BR, celebrado entre a ANS e o Banco Interamericano de Desenvolvimento (BID); estudos financiados pela OPAS sobre a regulação das relações entre o público e o privado nos sistemas de saúde de 10 países.

(7) Os hospitais dos servidores públicos atendem apenas aos funcionários públicos estaduais e seus familiares. Todos os demais bens de saúde ofertados pelo setor público são considerados SUS.

(8) No sistema anterior a assistência médica estava a cargo do Instituto Nacional de Assistência Médica da Previdência Social (Inamps) e se restringia aos empregados que contribuíssem com a previdência social.

(9) Em tese qualquer emergência deve ser tratada imediatamente, embora sejam comuns casos de falta de condições de atendimento em casos de emergência, que tornam patente a insuficiência da oferta pública de bens de saúde. 
de seguro/plano de saúde, por $35 \%$ dos gastos totais privados com saúde (Nishijima; Biasoto Jr., 2005) e detém elevadas proporções da infraestrutura de saúde no país (Datasus) - e de que operou livre de regulação específica por quarenta anos. As seguradoras em geral eram reguladas pela Superintendência de Seguros Privados (Susep), autarquia vinculada ao Ministério da Fazenda que, contudo, não possuía regras/normas específicas para o setor de saúde. A regulação ${ }^{10}$ mais sistemática e específica passou a ocorrer a partir do ano de 2000 com a criação da ANS, ${ }^{11}$ cujas implicações precisam ainda ser estudadas.

A estrutura produtiva peculiar do setor de saúde que se construiu no país parece ter contribuído para o aumento da desigualdade da distribuição de bens públicos de assistência médica, apesar da garantia do acesso universal e igualitário aos bens públicos de saúde pela Constituição de 1988.

Para testar essa hipótese - ou seja, se os consumidores de planos de saúde privados tiveram mais acesso aos bens de assistência médica com internações ofertados pelo setor público do que os não consumidores -, o presente artigo desenvolve uma análise econométrica utilizando os microdados da PNAD de 1998 com seu suplemento sobre saúde, e modelos probits e logits, dado que a variável dependente nos diferentes modelos tem caráter qualitativo. Essa base de dados, relativa a 1998, é ideal para a análise, uma vez que a regulação específica para o segmento privado ainda não havia sido estabelecida.

O artigo está estruturado em 5 seções (além desta introdução). A primeira apresenta uma caracterização da infraestrutura pública e privada do setor de saúde. A segunda seção apresenta a hipótese do artigo. A terceira seção apresenta o referencial teórico para análise do setor de saúde no Brasil e as adaptações necessárias para permitir o exercício analítico. A quarta seção apresenta estatísticas preliminares e a quinta seção apresenta os modelos estimados, além de discutir seus resultados; por fim, na última seção, as considerações finais são apresentadas.

\section{Caracterização da infraestrutura pública e privada de saúde no Brasil}

O arranjo produtivo do setor de saúde no país se constitui em um emaranhado de inter-relações entre setor público e privado. O SUS provê bens públicos de saúde por meio de instituições públicas, tais como hospitais, postos de saúde, e por meio das instalações de instituições privadas conveniadas ou contratadas. A Tabela 1 mostra o total de estabelecimentos de saúde existentes no

(10) Embora a Lei 6.565 de 1998 possa ser considerada como o marco da regulação, a unificação das atividades de regulação só ocorreu em 2001 após a criação da ANS, quando ocorreram ganhos de escala na realização destas atividades.

(11) Em novembro de 1999, a aprovação da Medida Provisória 1.928/99, convertida na Lei 9.961/00, criou a ANS e unificou o modelo bipartite de regulação proposto inicialmente pela Lei 9.656/98. A regulação passou a ser responsabilidade definitiva do Ministério da Saúde. 
país em 1999 por esfera administrativa. Verifica-se que a maioria dos estabelecimentos de saúde, 58,7\%, são públicos, e apenas a região sudeste apresenta maior percentual de estabelecimentos privados, 52,8\%. Além disso, o sistema público contrata ou usa sob convênio $31,2 \%$ dos estabelecimentos privados, sendo a região sudeste a que utiliza o menor percentual dos estabelecimentos do setor privado, $23,9 \%$, fenômeno associado ao maior tamanho do setor privado na região.

Tabela 1

Estabelecimentos de saúde, por esfera administrativa, segundo as Grandes Regiões e Brasil, 1999

\begin{tabular}{l|r|r|r|r|r|r|r}
\hline \multirow{2}{*}{$\begin{array}{l}\text { Brasil e Grandes } \\
\text { Regiões }\end{array}$} & \multicolumn{7}{|c}{ Estabelecimentos de saúde } \\
\cline { 2 - 8 } & \multirow{2}{*}{ Total } & Público & \multicolumn{2}{|c}{ Privado } & $\begin{array}{c}\% \\
\text { Público }\end{array}$ & $\%$ Privado \\
\cline { 3 - 8 } & & Total & \multicolumn{1}{|c}{ Total } & \multicolumn{1}{c}{ p/SUS } & Total & Total & $\begin{array}{c}\% \\
\text { p/SUS }\end{array}$ \\
\hline Brasil & 56.133 & 32.962 & 23.171 & 7.223 & $58,7 \%$ & $41,3 \%$ & $31,2 \%$ \\
\hline Norte & 4.645 & 3.732 & 913 & 298 & $80,3 \%$ & $19,7 \%$ & $32,6 \%$ \\
\hline Nordeste & 16.265 & 11.208 & 5.057 & 1.977 & $68,9 \%$ & $31,1 \%$ & $39,1 \%$ \\
\hline Sudeste & 21.483 & 10.130 & 11.353 & 2.708 & $47,2 \%$ & $52,8 \%$ & $23,9 \%$ \\
\hline Sul & 9.819 & 5.793 & 4.026 & 1.579 & $59,0 \%$ & $41,0 \%$ & $39,2 \%$ \\
\hline Centro-Oeste & 3.921 & 2.099 & 1.822 & 661 & $53,5 \%$ & $46,5 \%$ & $36,3 \%$ \\
\hline
\end{tabular}

Fonte: IBGE. Pesquisa de Assistência Médico-Sanitária (1999).

Por outro lado, se o SUS utiliza dependências privadas para atendimento de seus usuários, parece que o sistema privado também usa o SUS para a assistência de seus pacientes. Segundo Reis (2005), nesta mesma época existiam indícios desse tipo de ocorrências e discutia-se a dificuldade de ressarcimento das operadoras de seguros ao SUS pelo uso dos seus serviços, embora a magnitude desse uso fosse desconhecida. ${ }^{12}$ Esta autora discute tais problemas como sendo decorrentes da ausência de regulamentação específica para as operadoras privadas de saúde até junho de 1998, quando foi editada a Lei 9.656. Em seu artigo 32, esta lei instituiu o ressarcimento ao $\mathrm{SUS}^{13}$ dos gastos incorridos por pacientes de Planos de Saúde. A Lei 9.961 de 2000, que criou a ANS, determinou como

(12) A dificuldade de se conhecer sua magnitude ocorre por falta de condições de monitoramento, conforme será visto, e pelo grau variado de possibilidades do arranjo produtivo do setor. Por exemplo, um paciente com seguro privado pode ser atendido num hospital privado contratado pelo SUS, que pagará por este paciente, mas não receberá da operadora de seguro de saúde pelo tratamento.

(13) "Art. $32^{\circ}$. Serão ressarcidos pelas operadoras a que alude o art. $1^{\circ}$ os serviços de atendimento à saúde previstos nos respectivos contratos, prestados a seus consumidores e respectivos dependentes, em instituições públicas ou privadas, conveniadas ou contratadas, integrantes do Sistema Único de Saúde - SUS”. 
competência dessa agência o estabelecimento de normas para o ressarcimento do setor privado ao SUS.

Anteriormente a estas leis, a característica de universalidade do sistema público obviamente favorecia o uso do SUS pelo sistema privado, que não se via obrigado legalmente a realizar o ressarcimento das despesas de seus segurados. Além disso, de acordo com técnicos da ANS, ${ }^{14}$ muitos consumidores de planos privados de saúde que eram assistidos pelo SUS não eram nem identificados, pois inexistia um banco de dados de usuários de planos privados que pudesse ser cruzado com o banco de usuários do SUS. E, mesmo se esse banco existisse, ainda não seria possível a identificação do compartilhamento de pacientes, pois o banco do SUS, até a data desta legislação, tinha como chave de reconhecimento de paciente o nome do mesmo, gerando muitos problemas de homônimos. ${ }^{15}$

Neste artigo, a preocupação mais específica é com os tratamentos públicos que exigem internação, dados seus maiores custos quando comparados com custos de tratamentos ambulatoriais, embora o fenômeno possa ser mais amplo. Os médicos utilizam as denominações de complexidades baixas, médias e altas conforme a definição de procedimentos estabelecida pelo SUS, estando estas relacionadas aos custos do tratamento, mas os dados da PNAD não discriminam o tipo de procedimento específico recebido - apenas se cirurgia, parto ou exames.

A possível utilização do SUS pelo setor privado sem ressarcimento tinha implicações de bem estar sobre os agentes em todo o sistema de saúde brasileiro. No caso dos ofertantes privados, ao venderem planos de saúde com serviços que, em parte, eram cobertos pelo SUS, mas sem o devido ressarcimento, acabavam não incorrendo no custo social de sua produção. Pois parte de seus custos eram repassados para o sistema público. Isso fazia com que tendessem a ofertar uma quantidade de seguro privado além do socialmente desejado. Para o SUS não havia alívio da quantidade de pacientes tratados na magnitude do número de segurados, uma vez que mesmo aqueles com preço de reserva alto o suficiente para comprar planos privados de saúde, ao final, eram em parte atendidos pelo próprio SUS.

Do lado dos consumidores dos bens de saúde pode-se pensar em duas possibilidades decorrentes desse arranjo legal-produtivo: (i) os consumidores de seguros privados de saúde eram atendidos pelo SUS respeitando a fila de espera como os demais usuários do SUS; e (ii) os consumidores de seguros privados chegavam à fila de espera antes dos demais usuários do SUS. Existe um motivo para acreditar que a situação verificada no país até 2000 era a segunda alternativa: o setor privado de saúde seria o detentor da infraestrutura da diagnose no Brasil.

(14) Em entrevistas realizadas durante os estudos referentes ao convênio ATN/MT-6982-BR.

(15) Desde 2002 estão sendo realizados esforços conjuntos entre a ANS e o SUS para a composição de um cadastro comum de usuários dos dois sistemas de saúde, o público e o privado.

Economia e Sociedade, Campinas, v. 19, n. 3 (40), p. 589-611, dez. 2010. 
Para a obtenção de tratamentos saúde, o diagnóstico é uma condição necessária e, por sua vez, está vinculado à realização prévia de consultas médicas e de exames gerais e específicos que dependem crucialmente de equipamentos médicos. Assim, o diagnóstico depende do uso de bens de capital na forma de máquinas e equipamentos médicos que estão concentrados no setor privado de saúde (conforme pode ser visto na Tabela 2). O percentual de equipamentos médicos para diagnósticos no país, disponíveis ao setor público em estabelecimentos de saúde, corresponde a 54,2\% (19,3\% do setor público $+34,9 \%$ do setor privado disponível ao SUS). Quando se considera apenas os equipamentos em estabelecimentos de apoio à diagnose, este percentual apresenta maior concentração no setor privado, caindo para 34,8\% (6,7\% do setor público + $28,1 \%$ do setor privado disponível ao SUS).

Levando em conta que, em 1998, apenas $17,28 \%$ da população possuía plano privado de saúde (PNAD) e que a grande desigualdade de renda ${ }^{16}$ no país impede a opção por bens privados pelos pobres, a concentração da infraestrutura de diagnóstico na mão do setor privado tende a agravar a desigualdade de assistência entre pobres e ricos. ${ }^{17}$ Admitindo-se que a quantidade de seguros privados e a proporção de equipamentos médicos de propriedade pública e privada não se alteraram de 1998 para 1999, projeta-se que existia um (1) equipamento médico para diagnóstico para cada 1289 usuários exclusivos do SUS e um (1) equipamento para cada 319 consumidores de planos privados de saúde quando se considera todos os estabelecimentos de saúde; ${ }^{18}$ e ainda um (1) equipamento de diagnose para 5238 usuários exclusivos do SUS e um (1) para 585 usuários de planos privados, quando se considera somente as unidades de apoio à diagnose. $\mathrm{O}$ consumidor de plano privado de saúde, então, possui 4 vezes mais aparelhos para diagnóstico disponíveis nos estabelecimentos de saúde e quase 10 vezes mais aparelhos disponíveis nas unidades de apoio à diagnose quando comparado com os usuários exclusivos do SUS. Vale observar que estes valores atribuídos ao setor público estão ainda superestimados, porque uma parte dos seus aparelhos se destina exclusivamente à assistência ao funcionalismo público e, portanto, não estão disponíveis para a população em geral. ${ }^{19}$

(16) Como é sabido, a distribuição de renda no Brasil difere daquela de países como Estados Unidos e da Europa Ocidental pelo seu alto grau de desigualdade. De acordo com indicadores do Banco Mundial, no Brasil, em 2001, os $40 \%$ mais pobres detinham juntos $5,7 \%$ da renda total gerada no país, enquanto os $10 \%$ mais ricos detinham $46,7 \%$ do total da renda. Deste modo, para os mais pobres a possibilidade de escolha de consumo entre bens públicos e privados de saúde não está dada.

(17) Relatórios a este respeito podem ser encontrados no site www.ibge.gov.br.

(18) De acordo com a AMS, estabelecimento de saúde é aquele que presta serviços de saúde com um mínimo de técnica apropriada, segundo critérios estabelecidos pelo Ministério da Saúde, para atendimento rotineiro à população.

(19) Os dados da AMS de 1999 não fazem esta separação. 
Tabela 2

Equipamentos de diagnósticos por esfera administrativa em estabelecimentos de saúde e em estabelecimentos de apoio à diagnose no Brasil

\begin{tabular}{|c|c|c|c|c|c|c|c|c|}
\hline \multirow{3}{*}{ Tipo de equipamento } & \multicolumn{4}{|c|}{ Estabelecimentos de saúde } & \multicolumn{4}{|c|}{ Estabelecimentos de apoio à diagnose } \\
\hline & \multirow{2}{*}{ Total } & \multirow{2}{*}{ Público } & \multicolumn{2}{|c|}{ Privado } & \multirow{2}{*}{ Total } & \multirow{2}{*}{ Público } & \multicolumn{2}{|c|}{ Privado } \\
\hline & & & Total & SUS & & & Total & SUS \\
\hline Gama câmara & 748 & $18,9 \%$ & $81,1 \%$ & $40,4 \%$ & 329 & $1,8 \%$ & $98,2 \%$ & $39,8 \%$ \\
\hline Mamógrafo com comando & 1557 & $6,6 \%$ & $93,4 \%$ & $36,0 \%$ & 816 & $0,5 \%$ & $99,5 \%$ & $27,5 \%$ \\
\hline Mamógrafo com estereotaxia & 592 & $9,5 \%$ & $90,5 \%$ & $29,6 \%$ & 340 & $0,0 \%$ & $100,0 \%$ & $22,1 \%$ \\
\hline Raio $\mathrm{X}$ até $100 \mathrm{Ma}$ & 5925 & $27,3 \%$ & $72,7 \%$ & $42,8 \%$ & 541 & $5,0 \%$ & $95,0 \%$ & $19,6 \%$ \\
\hline Raio X de 100 a $500 \mathrm{~mA}$ & 7432 & $25,0 \%$ & $75,0 \%$ & $39,6 \%$ & 1439 & $1,5 \%$ & $98,5 \%$ & $34,1 \%$ \\
\hline Raio $\mathrm{X}$ mais de $500 \mathrm{~mA}$ & 2638 & $25,4 \%$ & $74,6 \%$ & $36,4 \%$ & 802 & $1,4 \%$ & $98,6 \%$ & $32,7 \%$ \\
\hline Raio X dentário & 7626 & $46,7 \%$ & $53,3 \%$ & $7,6 \%$ & 552 & $1,8 \%$ & $98,2 \%$ & $7,2 \%$ \\
\hline Raio X com fluoroscopia & 1129 & $18,7 \%$ & $81,3 \%$ & $41,9 \%$ & 327 & $0,3 \%$ & $99,7 \%$ & $32,1 \%$ \\
\hline Raio X para densidade óssea & 791 & $4,0 \%$ & $96,0 \%$ & $25,8 \%$ & 492 & $0,0 \%$ & $100,0 \%$ & $18,9 \%$ \\
\hline Raio X para hemodinâmica & 464 & $16,8 \%$ & $83,2 \%$ & $36,9 \%$ & 40 & $2,5 \%$ & $97,5 \%$ & $52,5 \%$ \\
\hline Tomógrafo computadorizado & 1555 & $9,5 \%$ & $90,5 \%$ & $41,2 \%$ & 667 & $0,7 \%$ & $99,3 \%$ & $34,5 \%$ \\
\hline Ressonância magnética & 289 & $6,6 \%$ & $93,4 \%$ & $35,6 \%$ & 149 & $0,7 \%$ & $99,3 \%$ & $28,9 \%$ \\
\hline Ultrassom doppler colorido & 3971 & $6,3 \%$ & $93,7 \%$ & $22,7 \%$ & 2169 & $0,5 \%$ & $99,5 \%$ & $13,0 \%$ \\
\hline Ultrassom ecógrafo & 7732 & $14,7 \%$ & $85,3 \%$ & $28,0 \%$ & 2864 & $0,6 \%$ & $99,4 \%$ & $15,6 \%$ \\
\hline Endoscópio das vias respiratórias & 1691 & $21,1 \%$ & $78,9 \%$ & $31,2 \%$ & 109 & $3,7 \%$ & $96,3 \%$ & $12,8 \%$ \\
\hline Endoscópio das vias urinárias & 1436 & $14,3 \%$ & $85,7 \%$ & $40,0 \%$ & 73 & $0,0 \%$ & $100,0 \%$ & $15,1 \%$ \\
\hline Endoscópio digestivo & 4836 & $18,3 \%$ & $81,7 \%$ & $34,1 \%$ & 726 & $1,2 \%$ & $98,8 \%$ & $18,2 \%$ \\
\hline Equipamento para optometria & 2014 & $17,4 \%$ & $82,6 \%$ & $26,3 \%$ & 80 & $0,0 \%$ & $100,0 \%$ & $25,0 \%$ \\
\hline Laparoscópio/vídeo & 2270 & $11,9 \%$ & $88,1 \%$ & $42,6 \%$ & 104 & $0,0 \%$ & $100,0 \%$ & $16,3 \%$ \\
\hline Microscópio cirúrgico & 3618 & $15,9 \%$ & $84,1 \%$ & $38,4 \%$ & 233 & $2,1 \%$ & $97,9 \%$ & $36,5 \%$ \\
\hline Eletrocardiógrafo & 15767 & $32,6 \%$ & $67,4 \%$ & $30,6 \%$ & 838 & $2,0 \%$ & $98,0 \%$ & $21,5 \%$ \\
\hline
\end{tabular}

Continua... 
Tabela 2 - Continuação

\begin{tabular}{|c|c|c|c|c|c|c|c|c|}
\hline \multirow{3}{*}{ Tipo de equipamento } & \multicolumn{4}{|c|}{ Estabelecimentos de saúde } & \multicolumn{4}{|c|}{ Estabelecimentos de apoio à diagnose } \\
\hline & \multirow{2}{*}{ Total } & \multirow{2}{*}{ Público } & \multicolumn{2}{|c|}{ Privado } & \multirow{2}{*}{ Total } & \multirow{2}{*}{ Público } & \multicolumn{2}{|c|}{ Privado } \\
\hline & & & Total & SUS & & & Total & SUS \\
\hline Eletroencefalógrafo & 1959 & $27,2 \%$ & $72,8 \%$ & $27,8 \%$ & 268 & $4,9 \%$ & $95,1 \%$ & $10,8 \%$ \\
\hline Equipamento de fototerapia & 8093 & $31,4 \%$ & $68,6 \%$ & $44,5 \%$ & 4605 & $32,1 \%$ & $67,9 \%$ & $40,6 \%$ \\
\hline Monitor de ECG & 26385 & $25,6 \%$ & $74,4 \%$ & $40,3 \%$ & 15962 & $27,4 \%$ & $72,6 \%$ & $35,4 \%$ \\
\hline Monitor de pressão invasivo & 4583 & $23,7 \%$ & $76,3 \%$ & $34,1 \%$ & 2755 & $26,7 \%$ & $73,3 \%$ & $27,5 \%$ \\
\hline Monitor de pressão não-invasivo & 10382 & $20,2 \%$ & $79,8 \%$ & $36,7 \%$ & 6470 & $21,3 \%$ & $78,7 \%$ & $31,2 \%$ \\
\hline Oxímetro & 21208 & $25,3 \%$ & $74,7 \%$ & $37,7 \%$ & 12240 & $25,3 \%$ & $74,7 \%$ & $33,5 \%$ \\
\hline $\begin{array}{c}\text { Aparelho de diatermia por } \\
\text { ultrassom/ondas curtas }\end{array}$ & 11758 & $15,4 \%$ & $84,6 \%$ & $27,1 \%$ & 5871 & $5,3 \%$ & $94,7 \%$ & $26,2 \%$ \\
\hline Aparelho de eletroestimulação & 8082 & $11,2 \%$ & $88,8 \%$ & $26,6 \%$ & 4666 & $4,0 \%$ & $96,0 \%$ & $24,2 \%$ \\
\hline $\begin{array}{l}\text { Bombas de infusão e } \\
\text { hemoderivados }\end{array}$ & 3023 & $28,8 \%$ & $71,2 \%$ & $34,0 \%$ & 147 & $19,7 \%$ & $80,3 \%$ & $39,5 \%$ \\
\hline Equipamento de aférese & 531 & $27,9 \%$ & $72,1 \%$ & $31,3 \%$ & 102 & $25,5 \%$ & $74,5 \%$ & $19,6 \%$ \\
\hline Equipamento para audiometria & 1920 & $16,8 \%$ & $83,2 \%$ & $17,4 \%$ & 379 & $4,5 \%$ & $95,5 \%$ & $12,7 \%$ \\
\hline $\begin{array}{l}\text { Equipamento para gasometria } \\
\text { sanguínea }\end{array}$ & 1665 & $25,4 \%$ & $74,6 \%$ & $43,4 \%$ & 173 & $0,0 \%$ & $100,0 \%$ & $38,7 \%$ \\
\hline Equipamento para hemodiálise & 7843 & $10,4 \%$ & $89,6 \%$ & $77,6 \%$ & 2070 & $2,6 \%$ & $97,4 \%$ & $86,4 \%$ \\
\hline Forno de Bier & 7948 & $18,0 \%$ & $82,0 \%$ & $34,2 \%$ & 3190 & $7,2 \%$ & $92,8 \%$ & $32,4 \%$ \\
\hline Média do país & & $19,3 \%$ & $80,7 \%$ & $34,9 \%$ & & $6,7 \%$ & $93,3 \%$ & $28,1 \%$ \\
\hline
\end{tabular}

Fonte: IBGE. Pesquisa de Assistência Médico-Sanitária (1999). 
Deste modo, pode-se propor a hipótese de que quem possui plano privado de saúde - indivíduos com maior preço de reserva e, portanto, com maior renda tem maior probabilidade de obter um diagnóstico médico mais rápido que os demais. Isto aumenta sua chance de receber um tratamento público com internação mais rapidamente que os demais, o que implica na obtenção de um tratamento de melhor qualidade..$^{20}$

\section{Objetivos e modelo de determinação do tratamento de saúde com internação}

O objetivo geral deste artigo é verificar empiricamente a hipótese estabelecida na seção anterior, sobre os bens de assistência médica que exigem internação, com o intuito de inferir se a estrutura produtiva do setor de saúde brasileiro promovia a desigualdade social na distribuição de bens de saúde público antes da regulação específica do setor.

O modelo inspirador da análise foi o de assistência à saúde pública e privada de Hoel e Sæther (2003), um modelo estocástico de maximização de bemestar de uma sociedade considerando a interação entre a oferta de tratamento do setor privado e do setor público. De acordo com os autores, um determinado tratamento de saúde, bem homogêneo, pode ser obtido alternativamente: com custo zero através do setor público e tempo T positivo de espera; ou através do setor privado com custo positivo e $\mathrm{T}=0$. $\mathrm{O}$ modelo pressupõe que o tempo de espera pelo tratamento público corresponde a um custo em termos de piora da condição de saúde do paciente, que pode ser avaliado diretamente como um custo monetário. Pode-se alternativamente dizer que ocorre perda de qualidade dos bens de saúde quando um longo tempo de espera se faz necessário, pois a espera pode causar a morte ou um dano irreversível à saúde. Deste modo, quando um indivíduo adoece - evento que está associado a uma determinada função densidade de probabilidade - compara o custo do tratamento privado de alta qualidade $(\mathrm{T}=0)$ com o custo do tempo de espera pelo tratamento do setor público de baixa qualidade $(\mathrm{T}>0)$, fazendo sua escolha de acordo com seu preço de reserva.

Dentro de um contexto de equilíbrio geral, os autores maximizam a função utilidade social impondo diferentes estruturas de pesos aos agentes econômicos, considerando que a oferta pública de bens de saúde é custeada totalmente pelo governo enquanto a oferta privada de bens de saúde pode ser tributada ou subsidiada. Quando atribuem pesos relativos maiores aos agentes de mais baixa renda, ${ }^{21}$ concluem que existir um tempo de espera positivo para o tratamento público é ótimo socialmente, uma vez que isso faz com que os agentes com maior

(20) Sob a hipótese de que um maior tempo de espera para o tratamento pode piorar o estado de saúde do indivíduo de maneira irreversível.

(21) Quando atribuem pesos iguais aos agentes não concluem que o tempo de espera positivo é ótimo. 
propensão a pagar pelo tratamento privado o façam. Deste modo, diminui a quantidade de usuários e, consequentemente, o tempo de espera para o tratamento do sistema público de saúde, o que implica numa melhora para os indivíduos de baixa renda, uma vez que tempo de espera é a medida da qualidade dos bens de saúde.

Embora este modelo seja útil para mostrar as interações entre um sistema público e um privado de saúde numa economia, apresenta algumas limitações analíticas para o caso brasileiro que devem ser consideradas. Ainda que no Brasil o sistema de saúde seja misto e exista um tempo de espera positivo para a obtenção de tratamento público, esta espera não deve resultar num ótimo para os tratamentos de saúde, mesmo que seja atribuído maior peso aos mais pobres. Pois, conforme visto na seção anterior, duas situações alteravam este quadro antes da regulação: primeiro, o consumidor de plano privado de saúde não estava excluído do consumo de bens públicos de saúde e o SUS, antes da regulação, não era ressarcido pelo setor privado; e segundo, o consumidor de plano privado tendia a chegar antes à fila do tratamento público através da obtenção mais rápida do seu diagnóstico. Assim, a existência de um setor privado de saúde não reduzia o tempo de espera para o tratamento público - $\mathrm{T}>0$ - para quem não tivesse plano privado de saúde.

A Figura 1 ilustra o problema. Suponha que dois pacientes, $p r$ que possui plano privado de saúde e $p u$ que não possui, passem mal em $\mathrm{t}_{0}$. Suponha também que a causa do mal-estar dos dois seja a mesma, um problema que exija uma intervenção cirúrgica para transplante de coração. Os dois pacientes entram na fila do diagnóstico em $\mathrm{t}_{0}$, desconhecendo a causa específica de seus males. $\mathrm{O}$ paciente $p r$ obtém o diagnóstico de seu mal-estar em $\mathrm{t}_{\text {Dpr }}$ num tempo menor que o de $p u$, em $t_{D p u}$. Diagnosticado em $t_{D p r}$, o paciente $p r$ entra na fila específica do transplante que ocorre em $\mathrm{T}_{\mathrm{pr}}$; já $p u$ entrará na fila de espera específica do transplante somente em $\mathrm{t}_{\text {Dpu }} \mathrm{e}$ obterá o tratamento em $\mathrm{T}_{\mathrm{pu}}$. Mesmo supondo (uma vez conhecido o diagnóstico) que o tempo de espera para o tratamento específico é o mesmo ${ }^{22}$ para os dois pacientes, $\Delta_{p r}=\Delta_{p u}$, tem-se que $\mathrm{T}_{\mathrm{pu}}>\mathrm{T}_{\mathrm{pr}}$. Isto é, o tratamento recebido pelo paciente exclusivo do SUS é de pior qualidade quando comparado ao caso em que este tivesse um plano privado de saúde.

(22) Existe a possibilidade de esse tempo diferir como decorrência da atuação simultânea de médicos nos dois sistemas, o que caracterizaria o fenômeno de "furar a fila" do tratamento público, mas esta questão precisa ainda ser investigada. 
Figura 1

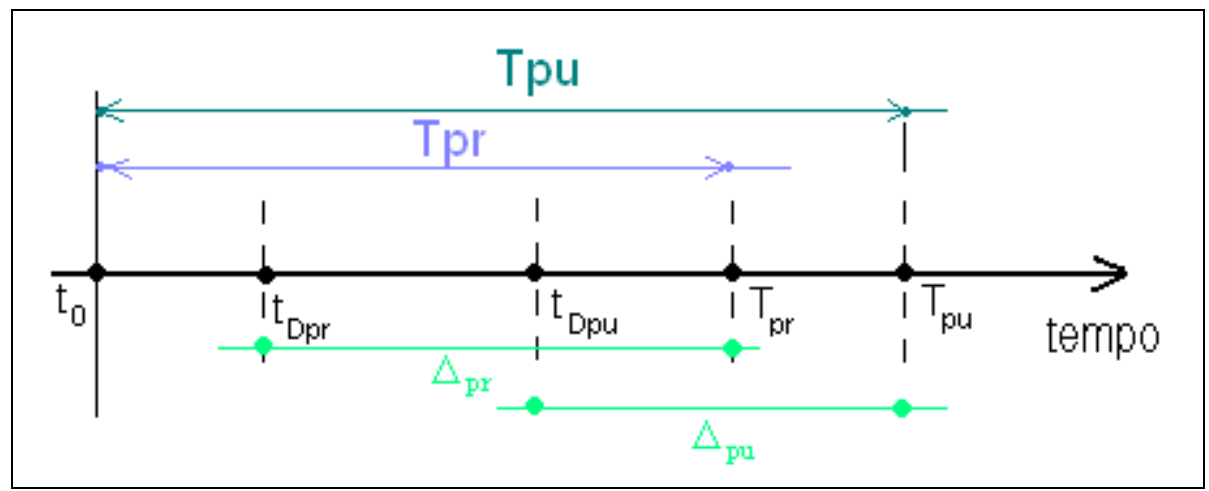

Fonte: Elaboração própria.

Do ponto de vista do modelo de Hoel e Sæther (2003), significa dividir o tempo $\mathrm{T}$ de espera para a obtenção de um tratamento público de saúde em duas partes, uma de diagnóstico e outra de espera pelo tratamento efetivo. Para simplificar a análise e discutir as implicações sobre o modelo destes autores, suporemos que $\mathrm{T} p r$ é igual a zero $(\mathrm{T} p r=\mathrm{T}=0)$ e que $\mathrm{T} p u$ é positivo $(\mathrm{T} p u=\mathrm{T}>0)$. Deste modo, o indivíduo representativo $p r$, que possui plano privado de saúde com tempo de espera de tratamento igual a zero, como decorrência de obtenção de diagnóstico num tempo menor que $p u$, chega mais rapidamente à fila de espera do tratamento público e, como consequência, obtém um tratamento de melhor qualidade. Vale observar que este resultado se deve exclusivamente à estrutura produtiva do setor de saúde montada no país e, portanto, apesar da regulação específica, continuará a ocorrer até que seja alterada a distribuição da diagnose.

Quando se considera a questão do não ressarcimento do setor privado ao SUS, que antes de 2000 era incipiente, a consequência do arranjo legal-produtivo, em que o setor privado usava a capacidade produtiva do setor público sem incorrer nos seus custos verdadeiros, era que o preço pago pelo tratamento de melhor qualidade não era revertido para a ampliação da capacidade produtiva do setor público, que permitiria a redução do tempo de espera pelo tratamento, melhorando a sua qualidade.

Levando em conta a falta de informações sobre tempo de espera até a obtenção de um tratamento público, foi necessário buscar dados que permitissem testar a hipótese de forma indireta. A utilização do microdados da PNAD de 1998 (incluindo o seu suplemento de saúde) permitiu o teste da hipótese em duas etapas. Em primeiro lugar, se os consumidores de seguros/planos privados de saúde são de fatos os mais ricos; e, uma vez comprovada essa relação, em segundo, comprovado que a renda determina a posse de seguros privados de saúde, verificar se a probabilidade de recebimento de tratamento público de saúde com internação 
é afetada positivamente pela posse do seguro privado de saúde. A hipótese nula, neste último caso, é a de que se não existe problema na distribuição dos bens públicos de saúde, então a posse de um seguro/plano de saúde não pode ser estatisticamente significativa para explicar a sua obtenção. Note que estas etapas são sequenciais e a primeira é condição necessária da segunda.

Esta metodologia envolve a estimação de um modelo de determinantes da posse do seguro privado de saúde e outro de determinantes do recebimento de um tratamento público com internação. O que foi realizado por meio de estimativas de modelos de probabilidade linear (MPL), logits e probits. O primeiro modelo consiste numa regressão linear em que a variável explicada é binária.

$$
P(y=1 \mid \mathbf{x})=G(\mathbf{x} \boldsymbol{\beta}) \equiv p(\mathbf{x})
$$

A equação (1) descreve os modelos logit e probit estimados, em que a variável dependente consiste numa dummy com valor igual a 1 se o fenômeno estudado se verifica. Assim, para o modelo de determinantes da posse do seguro, a variável dependente assume 1 se tem seguro, 0 caso contrário; 1 se recebeu um tratamento público com internação, 0 caso contrário. Tais modelos permitem medir as probabilidades condicionais no vetor de variáveis $\mathbf{x}(m \times n)$, com $m$ variáveis com amostras de tamanho $n$, que afetam as variáveis de interesse. Se a função G(.) for uma função densidade de probabilidade normal acumulada tem-se um modelo probit, e se for logística tem-se um modelo logit (Wooldbridge, 2002).

\section{Estatísticas preliminares sobre a saúde no Brasil}

De acordo com a PNAD de 1998, aproximadamente $24 \%$ dos brasileiros possuem plano de saúde, ${ }^{23}$ e destes, $72 \%$ possuem plano privado de saúde. Os demais $28 \%$ dos detentores de planos de saúde possuem plano de saúde associado ao funcionalismo público. ${ }^{24} \mathrm{~A}$ Tabela 3 mostra o percentual de indivíduos que possui planos de saúde por decil de renda e por região do país, revelando que os mais ricos são os maiores consumidores destes bens.

(23) Considerando os dependentes dos planos de saúde, este percentual corresponde a aproximadamente $37 \%$ da população com cobertura de plano de saúde. Mas, vale notar que esse percentual incorpora planos odontológicos, que são modalidades de planos, em geral, sem vínculos com os demais serviços de saúde.

(24) Basicamente os seguros dos servidores estaduais (Instituto de Assistência Médica ao Servidor Público Estadual) e os segurados da cooperativa de segurados do governo federal (A GEAP - Fundação de Seguridade Social), que pode ser considerado um seguro misto. 
Análise econômica da interação entre a infraestrutura da saúde pública e privada no Brasil

Tabela 3

Percentual de pessoas que possuem plano de saúde por decil de renda e por grandes regiões

\begin{tabular}{c|r|r|r|r|r}
\hline \multicolumn{6}{c}{ Percentual da população por decil de renda que possui plano de saúde } \\
\hline & Sudeste & Nordeste & Norte & Sul & Centro-Oeste \\
\hline Decil 1 & 5,3 & 0,66 & 4,33 & 3,54 & 2,82 \\
\hline Decil 2 & 8,7 & 2,57 & 3,99 & 6,47 & 7,82 \\
\hline Decil 3 & 12,48 & 2,9 & 7,36 & 9,76 & 11,56 \\
\hline Decil 4 & 19,08 & 4,25 & 9,67 & 10,5 & 16,34 \\
\hline Decil 5 & 24,56 & 6,34 & 11,13 & 15,3 & 19,17 \\
\hline Decil 6 & 30,47 & 9,35 & 15 & 19,8 & 26,74 \\
\hline Decil 7 & 36,62 & 13,17 & 20,19 & 23,93 & 35,25 \\
\hline Decil 8 & 46,38 & 21,41 & 27,23 & 35,8 & 40,27 \\
\hline Decil 9 & 55,53 & 35,52 & 35,52 & 46,72 & 52,98 \\
\hline Decil 10 & 77,41 & 65,37 & 55,25 & 67,27 & 69,61 \\
\hline
\end{tabular}

Fonte: Andrade e Lisboa (2000), informações retiradas da PNAD de 1998.

Um fator importante a ser observado é que o acesso da maioria dos brasileiros aos planos de saúde também está fortemente relacionado ao vínculo empregatício no setor formal da economia, fato comum a muitos outros países (Cutler; Gruber, 1996). Existem acordos, para os mais diferentes setores, via sindicatos, que vinculam o acesso a plano de saúde ao emprego, sendo que o empregador pode se responsabilizar total, parcial ou não se responsabilizar pelo pagamento das mensalidades dos planos de seus funcionários (neste último caso sendo apenas o mediador da compra). Na PNAD de 1998, nem todas as pessoas que declararam possuir plano de saúde descreveram sua forma de pagamento, mas entre os que o fizeram verifica-se que 59,62\% pagavam seu plano através da empresa. Isto sugere que grande parcela de consumidores de seguros está vinculada ao emprego formal e, por complemento, os empregados do setor informal da economia estão excluídos. De acordo com a PNAD de 1998, quem possui plano de saúde tem renda média mensal de $\mathrm{R} \$ 551,20$ e quem não possui apresenta renda média mensal de $\mathrm{R} \$ 151,87$.

As informações da Tabela 3 também colocam a questão de preferência revelada: se os bens públicos de saúde são um direito universal e estão disponíveis a preço zero, por que o agente econômico com renda alta demanda bens privados de saúde com preços positivos? A resposta pode ser dada com base no modelo apresentado na seção 3, e a razão seria a demanda por bens de saúde de melhor qualidade $(\mathrm{T}=0)$. $\mathrm{O}$ diferencial de qualidade entre os bens de saúde privado e público - respectivamente alta qualidade $(\mathrm{T}=0)$ e baixa qualidade $(\mathrm{T}>0)$ - explica o comportamento dos agentes.

Medidas do grau de utilização do SUS pelos pacientes do setor privado são difíceis de serem obtidas, conforme a impossibilidade de identificação de usuários descrita na Seção 2, o que constitui uma das principais dificuldades para 
possíveis cobranças de repasses de pagamentos do setor privado ao SUS. Para o período posterior ao investigado neste artigo, ainda é possível obter alguma informação $^{25}$ deste uso através da ação conjunta da ANS $^{26}$ com SUS para viabilizar tal ressarcimento, mas antes dessa data pouco se conhece sobre sua magnitude.

Apesar dessas dificuldades de obtenção do grau de utilização do SUS em tratamentos que envolvam internações pelas empresas privadas, no período préregulação, é possível combinar algumas informações do suplemento de saúde da PNAD de 1998 para obter algumas informações indiretas sobre esse grau. Uma primeira medida consiste em verificar as internações ocorridas nos últimos 12 meses da entrevista em hospitais públicos por pacientes que declararam possuir plano de saúde e plano de saúde privado, respectivamente a $10 \%$ e a $5,65 \%$ dos pacientes. Esta medida, entretanto, é subestimada, pois existem hospitais como as Santas Casas, que são entidades sem fins lucrativos, mas que são classificadas como privadas e são mantidas parcialmente pelo governo. Outra medida possível consiste em considerar a resposta à pergunta "Quando está doente ou precisando de atendimento de saúde, onde costuma procurar?": 41,94\% das pessoas responderam posto de saúde (que são instituições públicas), das quais 4,34\% possuem planos de saúde; se ao percentual de pessoas que procura posto de saúde forem somadas as pessoas que procuram ambulatório de hospital, obtém-se $63,95 \%$ das pessoas, das quais 10,59\% possuem planos de saúde.

No que se refere à assimetria de informação, que em tese justifica a imposição de preços altos de seguros (planos) de saúde ao mercado, os dados de 1998 da PNAD trazem informação indireta sobre o tema. A Tabela 4 sugere que no Brasil as seguradoras de saúde não incorrem no problema de seleção adversa. Nas duas primeiras colunas tem-se o percentual da avaliação que cada indivíduo faz de sua própria saúde de acordo com a população que possui um único seguro de saúde, $22,48 \%$, e com a população que possui mais de um seguro, $2 \%$. As demais colunas mostram a mesma distribuição, mas condicional, dado que as pessoas possuem algum plano de saúde. Estas informações devem ser consideradas com cautela, pois em países com elevado percentual de pobreza, os mais pobres tendem a reportar menos suas doenças que os mais educados e ricos, enviesando esta medida de autoavaliação de saúde (Strauss; Thomas, 1998).

(25) De acordo com a ANS, de 2000 até junho de 2002 foram cobrados 79.755 Avisos de Beneficiários Identificados, dos quais apenas $19.558(32,86 \%)$ foram ressarcidos, enquanto a parte não recebida se devia a entrada na justiça das operadoras privadas contra o Estado. Mas, grande parcela de usuários ainda não era identificável e a ANS argumenta que o ressarcimento completo exigiria o cruzamento de informações dos 34 milhões de consumidores de planos privados de saúde com o cadastro do SUS.

(26) Relatório de Gestão - Os 30 primeiros meses: janeiro de 2000 a julho de 2002, disponível no site www.ans.org.br. 
Análise econômica da interação entre a infraestrutura da saúde pública e privada no Brasil

Tabela 4

Autoavaliação do estado de saúde dos segurados de planos de saúde em 1998

\begin{tabular}{l|r|r|r|r}
\hline \multirow{2}{*}{$\begin{array}{l}\text { Auto- } \\
\text { avaliação }\end{array}$} & \multicolumn{2}{|c|}{$\%$ pop. que possui plano } & \multicolumn{2}{c}{$\begin{array}{c}\text { entre os que possuem } \\
\text { planos de saúde }\end{array}$} \\
\cline { 2 - 5 } & 1 plano & mais de 1 & 1 plano & mais de 1 \\
\hline Muito bom & 7,11 & 0,72 & 31,64 & 35,82 \\
\hline Bom & 11,56 & 1,01 & 51,44 & 50,34 \\
\hline Regular & 3,29 & 0,25 & 14,65 & 12,49 \\
\hline Ruim & 0,4 & 0,02 & 1,78 & 1,03 \\
\hline Muito ruim & 0,1 & 0,01 & 0,46 & 0,3 \\
\hline Ignorado & 0,01 & 0 & 0,02 & 0,01 \\
\hline Totais & 22,48 & 2 & 100 & 100 \\
\hline
\end{tabular}

Fonte: PNAD (1998).

Apesar desse problema, o cruzamento destas informações com as de planos de saúde permite a obtenção de medidas indiretas do perfil do consumidor do seguro de saúde, uma vez que os mais pobres têm pouco acesso aos planos de saúde, conforme Tabela 4. Nesta tabela vemos que 83,08\% $(31,64 \%+51,44 \%)$ das pessoas que possuem um plano de saúde avaliam seu estado de saúde como "bom" ou "muito bom"; já entre os indivíduos que possuem mais de um plano de saúde, $86,16 \%(35,82+50,34 \%)$ avaliam seu estado como "bom" ou "muito bom". Note que, neste último caso, apenas uma das seguradoras incorrerá nos custos de tratamento do paciente. Estes resultados sugerem, então, que a carteira das seguradoras de saúde, no Brasil, não é composta predominantemente por indivíduos com perfil indesejável.

\section{Estimativas econométricas}

\section{Primeira etapa}

Para avaliar os determinantes da posse de seguro/plano de saúde e de seguro/plano de saúde $^{27}$ privado no Brasil foram estimados modelos de probabilidade, respectivamente Tabelas 5 e 6: modelos lineares de probabilidade (MLP); modelos probit; e modelos logit - utilizando dados do suplemento de saúde e da PNAD de $1998 .^{28}$ O objetivo específico consistiu em verificar se a variável renda é estatisticamente significativa para a decisão de posse de planos privados de saúde no Brasil, tendo como base Costa (1995), que estima modelos probits para avaliar os determinantes da posse de seguro privado de saúde e contra acidentes na Califórnia.

(27) Neste caso, conforme discutido na seção 3, soma-se aos planos privados de saúde os planos de saúde de assistência de servidor público.

(28) Note que por se tratar de apenas uma PNAD, os modelos estimados constituem uma cross-section. 
Tabela 5

Estimativas de modelos de probabilidade para determinantes da posse de plano de saúde

\begin{tabular}{|c|c|c|c|c|c|c|c|}
\hline Dep. var. & \multicolumn{7}{|c|}{ Plano } \\
\hline Variables & MLP & $\mathrm{p}>|\mathrm{t}|$ & Probit & $\mathrm{dF} / \mathrm{dx}$ & $\mathrm{p}>|\mathrm{t}|$ & Logit & $\mathrm{p}>|\mathrm{t}|$ \\
\hline ymedia & $0,000244(21,32)$ & 0,000 & $0,0009269(12,30)$ & 0,000238 & 0,000 & $0,0019769(16,65)$ & 0,000 \\
\hline ymedia2 & $-1,40 \mathrm{e}-08(-5,69)$ & 0,000 & $-5,87 \mathrm{e}-08(-3,24)$ & $-1,51 \mathrm{E}-08$ & 0,001 & $-1,88 \mathrm{e}-07(-4,61)$ & 0,000 \\
\hline estudo & $0,02472(59,90)$ & 0,000 & $0,0926112(42,41)$ & 0,023825 & 0,000 & $0,1522395(50,18)$ & 0,000 \\
\hline agri & $-0,013785(-5,70)$ & 0,000 & $-0,3322958(-17,44)$ & $-0,07765$ & 0,000 & $-0,6263682(-17,53)$ & 0,000 \\
\hline crônica & $-0,006024(-2,87)$ & 0,004 & $-0,0112993(-1,22)$ & $-0,0029$ & 0,224 & $-0,0177957(-1,09)$ & 0,276 \\
\hline idade & $0,001304(4,58)$ & 0,000 & $0,0032863(2,10)$ & 0,000845 & 0,036 & $0,0082913(2,92)$ & 0,003 \\
\hline idade2 & $0,0000113(3,20)$ & 0,001 & $0,0000939(4,83)$ & $2,42 \mathrm{E}-05$ & 0,000 & $0,0001272(3,62)$ & 0,000 \\
\hline sexo & $-0,001866(-0,96)$ & 0,337 & $-0,0158421(-1,83)$ & $-0,00408$ & 0,068 & $-0,0164769(-1,08)$ & 0,279 \\
\hline urbana & $0,0335947(14,36)$ & 0,000 & $0,3048748(18,44)$ & 0,071861 & 0,000 & $0,5363832(17,32)$ & 0,000 \\
\hline consulta & $0,100696(51,69)$ & 0,000 & $0,446466(50,41)$ & 0,113617 & 0,000 & $0,8012407(50,73)$ & 0,000 \\
\hline tra1 & $0,102859(28,70)$ & 0,000 & $0,3273693(14,29)$ & 0,089013 & 0,000 & $0,6143227(15,45)$ & 0,000 \\
\hline $\operatorname{tra} 2$ & $0,281603(49,75)$ & 0,000 & $0,7657105(28,67)$ & 0,25064 & 0,000 & $1,348898(29,33)$ & 0,000 \\
\hline $\operatorname{tra} 3$ & $-0,027150(-8,83)$ & 0,000 & $-0,2053559(-8,41)$ & $-0,05031$ & 0,000 & $-0,3057401(-7,20)$ & 0,000 \\
\hline tra4 & $-0,029917(-9,63)$ & 0,000 & $-0,2058257(-8,84)$ & $-0,05047$ & 0,000 & $-0,3227986(-7,95)$ & 0,000 \\
\hline tra5 & $0,0279672(4,14)$ & 0,000 & dropped & Dropped & & Dropped & \\
\hline $\operatorname{tra6}$ & dropped & & $-0,096337(-3,16)$ & $-0,02384$ & 0,002 & $-0,123189(-2,25)$ & 0,024 \\
\hline cte & $-0,14436(-25,31)$ & 0,000 & $-2,434801(-56,73)$ & & 0,000 & $-4,333208(-55,81)$ & 0,000 \\
\hline \multirow[t]{5}{*}{ n. obs. } & \multicolumn{2}{|l|}{156841} & \multicolumn{3}{|c|}{156841} & \multicolumn{2}{|l|}{156841} \\
\hline & \multicolumn{2}{|c|}{ Test $\mathrm{F}=5174,09$} & \multicolumn{3}{|c|}{ Wald chi2(15)=31573,71 } & \multicolumn{2}{|c|}{ Wald chi2 $2(15)=28832,26$} \\
\hline & \multicolumn{2}{|c|}{ Prob $>F=0,000$} & \multicolumn{3}{|c|}{ Prob $>$ chi $2=0,0000$} & \multicolumn{2}{|c|}{ Prob $>$ chi $2=0,0000$} \\
\hline & \multicolumn{2}{|c|}{ R-squared=0,3208 } & \multicolumn{3}{|c|}{ Pseudo R2=0,3119 } & \multicolumn{2}{|c|}{ Pseudo R2=0,3150 } \\
\hline & \multicolumn{2}{|c|}{ Root MSE $=0,35447$} & \multicolumn{3}{|c|}{ Log likelihood=-60085,472 } & \multicolumn{2}{|c|}{ Log likelihood $=-59815,06$} \\
\hline
\end{tabular}

para o modelo probit, $\mathrm{dF} / \mathrm{dx}$ descreve as probabilidades. 
Além do MPL, a equação (1) descreve os modelos de respostas binárias estimados, em que a variável dependente consiste numa dummy com valor igual a 1 , se o indivíduo possui seguro/plano de saúde, e 0 caso contrário. O vetor $\mathbf{x}$ contém as seguintes variáveis explicativas: ymedia $a_{i}$ renda média mensal do indivíduo i - renda da família dividida pelo seu número de componentes; estudo, número de anos de estudo do indivíduo i - variável usada como proxy para o grau de informação de um indivíduo sobre o mercado de bens de saúde; $a g r i i_{i}$, variável binária que descreve se o indivíduo trabalha em atividade agrícola ou não; crônica ${ }_{i}$, variável binária que descreve se o indivíduo i possui alguma doença crônica; ${ }^{29}{ }^{2}$ dade $_{i}$, variável com a idade do indivíduo i; idade $2_{i}$, variável idade elevada ao quadrado; $\operatorname{sexo}_{i}$, variável com o sexo do indivíduo i 1 se masculino, 0 se feminino; urbana $_{i}$, variável que indica se o indivíduo i mora na zona urbana ou rural; consulta $_{i}$, variável binária que descreve se o indivíduo i consultou um médico no último ano ou não; $\mathrm{tra}_{i}$, variáveis dummies que indicam se o indivíduo i trabalha com carteira assinada, se é funcionário público, se trabalha sem carteira assinada, se trabalha por conta própria, se é empregador e se trabalha sem remuneração.

O MLP, estimado por Mínimos Quadrados Ordinários (OLS) apresenta heteroscedasticidade intrínseca, por isso estimou-se tal modelo usando matriz de covariância corrigida pelo procedimento de White (Johnston; Dinardo, 1997). Os modelos probit e logit também foram corrigidos por heteroscedasticidade.

As estimativas obtidas sugerem que a renda do indivíduo afeta positivamente a sua probabilidade de possuir um seguro de saúde, em acordo com as informações da Tabela 3, que mostra que os mais ricos são os possuidores de seguros de saúde. Mas, o aumento da probabilidade decorrente do aumento de renda ocorre em taxas decrescentes, o que indica que, se o indivíduo for muito rico, poderá ser desestimulado a possuir um plano.

Os demais resultados evidenciados pelos modelos estimados foram: i) se o indivíduo trabalha no setor formal da economia ou é funcionário público, sua probabilidade de possuir um seguro aumenta; ii) se trabalha para o setor informal ou por conta própria sua probabilidade de possuir um seguro de saúde diminui; iii) a idade do indivíduo e sua idade ao quadrado afetam positivamente sua probabilidade de possuir um seguro de saúde; iv) a variável que mede o grau de formação dos agentes - que sugere que quanto mais bem informado for um indivíduo maior a sua probabilidade de possuir um seguro de saúde - afeta positivamente a probabilidade de obter seguro; v) se o indivíduo mora em região urbana, sua probabilidade de possuir um seguro de saúde é maior que a de um

(29) Esta variável foi construída com base nas variáveis v1309 a v1320 do suplemento de saúde da PNAD de 1998, que buscam inferir se o entrevistado possui alguma doença crônica.

Economia e Sociedade, Campinas, v. 19, n. 3 (40), p. 589-611, dez. 2010. 
morador da região rural; vi) o fato do indivíduo trabalhar para o setor agrícola reduz sua probabilidade de possuir seguro de saúde; vii) e, por último, o fato do indivíduo ter consultado um médico nos últimos 12 meses anteriores à entrevista do IBGE aumenta a sua probabilidade de possuir um seguro. Os itens sexo e existência de doença crônica não se mostraram estatisticamente significativos.

Os resultados das estimativas dos determinantes do seguro de saúde privado, ou seja, quando se exclui dos seguros de saúde os planos de saúde dos servidores públicos, foram bastante semelhantes (ver Tabela 6). As diferenças foram: i) a idade ao quadrado se mostrou estatisticamente significativa; ii) a existência de alguma doença crônica se mostrou estatisticamente significativa sobre a probabilidade da posse de um plano de saúde privado; iii) e o fato do indivíduo ser funcionário público passou a diminuir sua probabilidade de possuir seguro de saúde privado.

Tabela 6

Estimativas de modelos de probabilidade para determinantes da posse de plano de saúde privado

\begin{tabular}{|c|c|c|c|c|c|c|c|}
\hline \multirow{2}{*}{$\begin{array}{l}\text { Dep. } \\
\text { Var. } \\
\text { Variables }\end{array}$} & \multicolumn{7}{|c|}{ Plapri } \\
\hline & MLP & $\mathrm{p}>|\mathrm{t}|$ & Probit & $\mathrm{dF} / \mathrm{dx}$ & $\mathrm{p}>|\mathrm{t}|$ & Logit & $\mathrm{p}>|\mathrm{t}|$ \\
\hline ymedia & $0,00022(22,28)$ & 0,000 & $0,0006786(10,33)$ & 0,000132 & 0,000 & $0,0014484(13,23)$ & 0,000 \\
\hline ymedia2 & $-1,21 \mathrm{e}-08(-5,85)$ & 0,000 & $-4,57 \mathrm{e}-08(-3,09)$ & $-8,92 \mathrm{E}-09$ & 0,002 & $-1,51 \mathrm{e}-07(-5,08)$ & 0,000 \\
\hline estudo & $0,0185891(49,72)$ & 0,000 & $0,083272(37,17)$ & 0,016237 & 0,000 & $0,1397952(40,32)$ & 0,000 \\
\hline agri & $-0,0122864(-5,68)$ & 0,000 & $-0,3487409(-17,31)$ & $-0,06002$ & 0,000 & $-0,7534867(-18,31)$ & 0,000 \\
\hline crônica & $-0,0077852(-3,89)$ & 0,000 & $-0,02523(-2,62)$ & $-0,0049$ & 0,009 & $-0,0448077(-2,58)$ & 0,010 \\
\hline idade & $0,0019046(7,28)$ & 0,000 & $0,0086487(5,20)$ & 0,001686 & 0,000 & $0,0171841(5,49)$ & 0,000 \\
\hline idade2 & $-4,10 \mathrm{e}-06(-1,26)$ & 0,207 & $8,92 \mathrm{e}-06(0,43)$ & $1,74 \mathrm{E}-06$ & 0,668 & $-0,0000153(-0,39)$ & 0,696 \\
\hline sexo & $-0,0019126(-1,04)$ & 0,300 & $-0,0167132(-1,86)$ & 0,001762 & 0,063 & $-0,0159764(-0,99)$ & 0,324 \\
\hline urbana & $0,0215607(10,46)$ & 0,000 & $0,2792622(15,98)$ & 0,049307 & 0,000 & $0,5415144(15,32)$ & 0,000 \\
\hline consulta & $0,0831365(45,87)$ & 0,000 & $0,4147799(44,61)$ & 0,080181 & 0,000 & $0,7641666(44,96)$ & 0,000 \\
\hline tra1 & $0,1052704(31,33)$ & 0,000 & $0,2047366(9,29)$ & 0,041818 & 0,000 & $0,383365(9,88)$ & 0,000 \\
\hline tra2 & $-0,109204(-22,18)$ & 0,000 & $-0,6676224(-26,02)$ & $-0,09013$ & 0,000 & $-1,189361(-26,39)$ & 0,000 \\
\hline tra3 & $-0,0310124(-11,14)$ & 0,000 & $-0,4232395(-17,79)$ & $-0,00361$ & 0,000 & $-0,7391905(-17,49)$ & 0,000 \\
\hline tra4 & $-0,0243397(-8,54)$ & 0,000 & $-0,3423711(-15,18)$ & $-0,06043$ & 0,000 & $-0,5847336(-14,72)$ & 0,000 \\
\hline tra5 & $0,0559329(8,35)$ & 0,000 & Dropped & dropped & & dropped & \\
\hline tra6 & Dropped & & $-0,2416909(-7,91)$ & $-0,04156$ & 0,000 & $-0,4189193(-7,34)$ & 0,024 \\
\hline cte & $-0,1240155(-23,91)$ & 0,000 & $-2,357891(-53,93)$ & & 0,000 & $-4,230247(-51,91)$ & 0,000 \\
\hline \multirow[t]{5}{*}{ n. obs. } & \multicolumn{2}{|l|}{156841} & \multicolumn{3}{|c|}{156841} & \multicolumn{2}{|l|}{156841} \\
\hline & \multicolumn{2}{|l|}{ Test $\mathrm{F}=2510,77$} & \multicolumn{3}{|c|}{ Wald chi $2(15)=24474,83$} & \multicolumn{2}{|c|}{ Wald chi2 $(15)=22497,23$} \\
\hline & \multicolumn{2}{|l|}{ Prob $>F=0,000$} & \multicolumn{3}{|c|}{ Prob $>$ chi $2=0,0000$} & \multicolumn{2}{|c|}{ Prob $>$ chi $2=0,0000$} \\
\hline & \multicolumn{2}{|c|}{ R-squared=0,2295 } & \multicolumn{3}{|c|}{ Pseudo R2=0,2482 } & \multicolumn{2}{|c|}{ Pseudo R2 $=0,2492$} \\
\hline & \multicolumn{2}{|c|}{ Root MSE $=0,33567$} & \multicolumn{3}{|c|}{ Log likelihood $=-55198,26$} & \multicolumn{2}{|c|}{ Log likelihood $=-55119,894$} \\
\hline
\end{tabular}

Os valores descritos abaixo dos modelos são os coeficientes estimados, e entre parênteses estão as respectivas estatísticas " $\mathrm{t}$ ”; para o modelo probit, $\mathrm{dF} / \mathrm{dx}$ descreve as probabilidades.

Assim, em ambos os modelos a renda se mostrou um determinante significativo da posse de seguros de saúde, de modo que os mais ricos apresentam maior probabilidade de possuir seguro/plano de saúde. Este fenômeno é possivelmente explicado pela má qualidade dos bens públicos de saúde $(\mathrm{T}>0)$, derivada do tempo positivo de espera para obtenção do tratamento. 


\section{Segunda etapa}

O modelo de determinantes da obtenção de tratamento público de saúde com internação foi estimado por modelos de probabilidade, tendo como variável explicada o consumo de tratamentos com internação e, entre as suas variáveis explicativas, a posse de seguro/plano de saúde. Assim, foram estimados modelos probits (Tabelas 7 e 8 ) tendo como variável dependente a variável interna 1 se o indivíduo foi internado no último ano antes da entrevista e 0 caso contrário.

Tabela 7

Determinantes da obtenção de tratamento público de saúde com internação inclusive partos

\begin{tabular}{|c|c|c|c|c|c|c|c|}
\hline \multicolumn{8}{|c|}{ Modelo probit } \\
\hline \multirow[t]{2}{*}{ Dep. var. } & \multicolumn{7}{|c|}{ Interna } \\
\hline & \multicolumn{2}{|l|}{ Modelo A } & \multirow[b]{2}{*}{$\mathrm{p}>|\mathrm{z}|$} & \multirow[b]{2}{*}{ Variables } & \multicolumn{3}{|c|}{ Modelo B } \\
\hline Variables & coef. (test-z) & $\mathrm{dF} / \mathrm{dx}$ & & & coef. (test-z) & $\mathrm{dF} / \mathrm{dx}$ & $\mathrm{p}>|\mathrm{z}|$ \\
\hline plapri & $0,068123(4,58)$ & 0,004940 & 0,00 & Plano & $0,097185(6,79)$ & 0,0070758 & 0,00 \\
\hline ymedia & $-0,000022(-1,53)$ & $-0,000002$ & 0,13 & Ymedia & $-0,0000261(-1,80)$ & $-1,81 \mathrm{E}-06$ & 0,07 \\
\hline self & $0,207192(25,69)$ & 0,014419 & 0,00 & Self & $0,208340(25,79)$ & 0,0144726 & 0,00 \\
\hline crônica & $0,07842(6,12)$ & 0,005560 & 0,00 & Crônica & $0,078323(6,11)$ & 0,0055432 & 0,00 \\
\hline idade & $-0,0192473(-11,08)$ & $-0,001339$ & 0,00 & idade & $-0,019660(-11,36)$ & $-0,0013657$ & 0,00 \\
\hline idade2 & $0,000202(9,5)$ & 0,000014 & 0,00 & idade 2 & $0,000204(9,60)$ & 0,0000142 & 0,00 \\
\hline sexo & $-0,227053(-20,36)$ & $-0,016477$ & 0,00 & Sexo & $-0,227017(-20,36)$ & $-0,0164457$ & 0,00 \\
\hline urbana & $-0,010169(-0,56)$ & $-0,000712$ & 0,57 & Srbana & $-0,012293(-0,68)$ & $-0,0008597$ & 0,50 \\
\hline consulta & $1,247678(66,47)$ & 0,095394 & 0,00 & Consulta & $1,244182(66,20)$ & 0,0949172 & 0,00 \\
\hline educa & $-0,007092(-4,24)$ & $-0,000494$ & 0,00 & Educa & $-0,009143(-5,30)$ & $-0,0006352$ & 0,00 \\
\hline agri & $0,101637(5,44)$ & 0,007484 & 0,00 & Agri & $0,104984(5,61)$ & 0,0077317 & 0,00 \\
\hline cte & $-2,424548(-56,82)$ & & 0,00 & Cte & $-2,411388(56,53)$ & & 0,00 \\
\hline \multirow[t]{5}{*}{ n. obs. } & \multicolumn{3}{|c|}{156799} & n. obs. & \multicolumn{3}{|c|}{156799} \\
\hline & \multicolumn{3}{|c|}{ Wald chi2 $(11)=7059,55$} & & \multicolumn{3}{|c|}{ Wald chi2 $(11)=7214,24$} \\
\hline & \multicolumn{3}{|c|}{ Prob $>$ chi $2=0,0000$} & & \multicolumn{3}{|c|}{ Prob $>$ chi $2=0,0000$} \\
\hline & \multicolumn{3}{|c|}{ Pseudo R2=0,1588 } & & \multicolumn{3}{|c|}{ Pseudo R2=0,1582 } \\
\hline & \multicolumn{3}{|c|}{ Log likelihood=-31352,765 } & & \multicolumn{3}{|c|}{ Log likelihood=-32306,981 } \\
\hline
\end{tabular}

$\mathrm{dF} / \mathrm{dx}$ descreve as probabilidades dos valores discretos do modelo probit estimado.

Além disso, como na PNAD é possível separar a variável internação pelos motivos da internação, também foram estimados modelos com internação exclusive partos como variável dependente $\left(\right.$ inter $\left._{i}\right)$, conforme Tabela 8 , e as seguintes variáveis independentes: plano $_{i}$, que descreve se o indivíduo i possui ou não plano de saúde (alternativamente, plapri $_{i}$, que considera apenas se o indivíduo i possui plano privado); ymedia $_{i}$, que recupera a renda domiciliar per capita do indivíduo i; self $f_{i}$, variável categórica que descreve a autoavaliação do estado de saúde de cada indivíduo i, que é usada como proxy do estado de saúde do indivíduo; cronica $_{i}$, variável que descreve se o indivíduo i possui alguma doença crônica; ${ }^{30}{ }_{i d a d e}$,

(30) Esta variável foi construída com base nas variáveis v1309 a v1320 do suplemento de saúde da PNAD de 1998, que buscam inferir se o entrevistado possui alguma doença crônica. 
variável com a idade do indivíduo i; idade ${ }_{i}$, variável idade elevada ao quadrado; sexo $_{i}$, variável com o sexo do indivíduo i - 1 se masculino, 0 se feminino; urbana $_{i}$, variável que indica se o indivíduo i mora na zona urbana ou rural; consulta ${ }_{i}$, variável binária que descreve se o indivíduo i consultou um médico no último ano ou não; $e^{2} u c a_{i}$, que descreve o número de anos de estudos completos; agri, variável binária que descreve se o indivíduo trabalha ou não em atividade agrícola.

Os resultados dos modelos estimados (Tabela 7) sugerem que o fato do indivíduo possuir seguro de saúde privado (modelo A) ou algum tipo de seguro/plano de saúde (modelo B) afeta positivamente sua probabilidade de receber um tratamento público com internação. Assim, considerando que o direito aos bens de saúde é universal, este resultado sugere um favorecimento ao acesso destes bens públicos de saúde aos indivíduos que possuem planos privados de saúde, em detrimento dos consumidores de baixa renda que precisam esperar na fila para obter o mesmo tratamento, o que resulta em pior qualidade de tratamento.

Quando são consideradas as internações exclusive os partos (Tabela 8), os resultados não se alteram significativamente além do esperado - modelos $\mathrm{C}$ e $\mathrm{D}$, respectivamente. Deste modo, quando os partos estão incluídos nas internações (modelos da Tabela 7), o fato de ser do sexo masculino diminui a probabilidade de internação, conforme pode ser verificado.

Tabela 8

Determinantes da obtenção de tratamento público de saúde com internação exclusive partos

\begin{tabular}{|c|c|c|c|c|c|c|c|}
\hline \multicolumn{8}{|c|}{ Modelo probit } \\
\hline \multirow[t]{2}{*}{ dep. var. } & \multicolumn{7}{|c|}{ Interna } \\
\hline & \multicolumn{2}{|c|}{ Modelo C } & & & \multicolumn{2}{|l|}{ Modelo D } & \multirow[b]{2}{*}{$\mathrm{p}>|\mathrm{z}|$} \\
\hline Variables & coef. (test-z) & $\mathrm{dF} / \mathrm{dx}$ & $\mathrm{p}>|\mathrm{z}|$ & Variables & coef. (test-z) & $\mathrm{dF} / \mathrm{dx}$ & \\
\hline plapri & $0,083619(5,19)$ & 0,0046311 & 0,00 & Plano & $0,1449364(9,39)$ & 0,008163 & 0,00 \\
\hline ymedia & $0,000020(1,74)$ & $0,1.04 \mathrm{e}-06$ & 0,08 & & $0,000013(1,09)$ & $6,72 \mathrm{E}-07$ & 0,28 \\
\hline self & $0,280767(32,31)$ & 0,0147213 & 0,00 & Self & $0,283388(32,54)$ & 0,0147864 & 0,00 \\
\hline crônica & $0,137325(9,80)$ & 0,0074666 & 0,00 & Crônica & $0,137608(9,81)$ & 0,0074465 & 0,00 \\
\hline idade & $-0,008561(-4,43)$ & $-0,0004489$ & 0,00 & Idade & $-0,009284(-4,80)$ & $-0,0004844$ & 0,00 \\
\hline idade2 & $0,000129(5,68)$ & $6,76 \mathrm{E}-06$ & 0,00 & idade2 & $0,000133(5,86)$ & $6,94 \mathrm{E}-06$ & 0,00 \\
\hline sexo & $0,0544595(4,44)$ & 0,0028293 & 0,00 & Sexo & $0,0550982(4,49)$ & 0,0028483 & 0,00 \\
\hline urbana & $0,017766(0,91)$ & 0,0009218 & 0,36 & Urbana & $0,0134392(0,69)$ & 0,0006957 & 0,49 \\
\hline consulta & $1,193902(56,51)$ & 0,06994 & 0,00 & Consulta & $1,187208(56,10)$ & 0,0691434 & 0,00 \\
\hline educa & $-0,005710(-3,21)$ & $-0,0002994$ & 0,00 & Educa & $-0,009307(-5,06)$ & $-0,0004856$ & 0,00 \\
\hline agri & $0,108967(5,46)$ & 0,0061008 & 0,00 & Agri & $0,115378(5,76)$ & 0,006454 & 0,00 \\
\hline cte & $-3,192995(-64,16)$ & & 0,00 & Cte & $-3,172387(-63,80)$ & & 0,00 \\
\hline n. obs. & \multicolumn{3}{|c|}{156799} & n. obs. & \multicolumn{3}{|c|}{156799} \\
\hline \multicolumn{4}{|c|}{ Wald chi2 $(11)=5777,74$} & \multicolumn{4}{|c|}{ Wald chi2 $(11)=5795,90$} \\
\hline \multicolumn{4}{|c|}{ Prob $>$ chi $2=0,0000$} & \multicolumn{4}{|c|}{ Prob $>$ chi $2=0,0000$} \\
\hline \multicolumn{4}{|c|}{ Pseudo R2=0,1655 } & \multicolumn{4}{|c|}{ Pseudo R2=0,1664 } \\
\hline \multicolumn{4}{|c|}{ Log likelihood=-25829,513 } & \multicolumn{4}{|c|}{ Log likelihood=-25798,972 } \\
\hline
\end{tabular}

$\mathrm{dF} / \mathrm{dx}$ descreve as probabilidades do modelo probit estimado. 
Os modelos estimados também revelam outras variáveis que afetam a probabilidade de consumo de tratamentos públicos com internação, enumeradas no parágrafo abaixo. Vale observar que os resultados destes modelos são robustos às especificações que incluem os estados de origem dos pacientes, sendo tais variáveis estatisticamente não significativas, sugerindo não haver diferenças regionais neste padrão. Considerando que o objetivo destes modelos era testar a significância da posse do plano privado de saúde sobre o consumo de tratamentos públicos, tais modelos podem ser considerados robustos na medida em que a inclusão destas variáveis adicionais não afetou o valor do coeficiente de interesse estimado.

A significância com sinal positivo da variável que mede o estado de saúde do indivíduo, self $_{i}$, cuja proxy utilizada foi a autoavaliação (ver Tabela 4), sugere que esta variável é uma boa representação da composição de tipos de consumidores das carteiras das seguradoras de saúde no Brasil. O que implica que a carteira das seguradoras privadas de saúde possui um perfil desejado de consumidores no que se refere ao estado de saúde destes indivíduos, ou seja, não há evidência de seleção adversa no mercado de seguro de saúde. A pré-existência de doença crônica ${ }^{31}$ afeta positivamente a probabilidade de receber um tratamento público com internação. Consultas médicas no ano anterior à entrevista da PNAD se mostraram significativas em aumentar a probabilidade de internação, conforme esperado. Um resultado surpreendente foi o sinal negativo do coeficiente associado à variável idade, indicando que quanto mais idosa for uma pessoa menor a sua probabilidade de receber um tratamento com internação, o que pode refletir o fato do idoso não sobreviver. O fato de o indivíduo residir em região urbana também aumenta sua probabilidade de receber um tratamento com internação, provavelmente refletindo a proximidade e localização dos locais de atendimento. $\mathrm{O}$ grau de informação dos agentes afeta negativamente a probabilidade de receber um tratamento com internação, provavelmente indicando tratamentos preventivos prévios.

\section{Considerações finais}

A organização do setor produtivo de bens e serviços de assistência médica, envolvendo além do setor público um segmento privado, embora com caráter de suplemento, tendia a ofertar bens de saúde em quantidades acima do socialmente desejado, causando problemas de eficiência econômica e de distribuição. Isso ocorria porque o setor privado não arcava, até o início da regulação pela ANS, com os custos reais dos tratamentos ofertados na forma de seguros/planos de saúde, jogando parte de seus custos para o setor público.

(31) Vale notar que, até o início da regulação pela a ANS, as doenças pré-existentes não eram cobertas pelos seguros de saúde. 
Além disso, como o setor privado de saúde era detentor da maioria dos centros de diagnóstico no país (associados ao direito universal à assistência de saúde pública), a posse de seguro/plano de saúde privado possibilitava que seus consumidores chegassem à frente da fila do tratamento público com internação.

Os testes empíricos e as estatísticas sugerem evidências favoráveis à hipótese de que os detentores de planos privados de saúde tinham mais acesso aos tratamentos públicos de saúde. Os resultados mostram que os seguros/planos privados de saúde são basicamente consumidos pelos mais ricos, e que a posse destes seguros/planos aumenta a probabilidade de se obter um tratamento público com internação.

Os resultados empíricos também sugerem um conjunto de características adicionais que podem direcionar uma agenda de pesquisas sobre o setor. Uma primeira linha de pesquisa seria testar os resultados aqui obtidos de maneira direta; por exemplo, realizando pesquisa primária ou explorando outros bancos de dados. Outra linha de pesquisa consistiria em investigar os efeitos da regulamentação da ANS sobre o setor. Por fim, outras possibilidades seriam superar algumas limitações presentes neste artigo, como, por exemplo, estudar os agentes do setor privado de saúde.

\section{Referências bibliográficas}

ALMEIDA, C. O mercado privado de serviços de saúde no Brasil: panorama atual e tendências da Assistência Médica Suplementar. Rio de Janeiro: Ipea, 1998. (Texto para Discussão, n. 599).

ANDRADE, M.; LISBOA, M. Sistema privado de seguro de saúde: lições do caso americano. Revista Brasileira de Economia, v. 54, n. 1, p. 5-36, 2000.

ARROW, K. J. Uncertainty and the welfare economics of medical care. The American Economic Review, v. 53, n. 5, 1963.

BIASOTO JUNIOR, G. Em busca de novas garantias e de eficiência na gestão. In: REZENDE, F.; CUNHA, A. O orçamento público e a transição do Poder, São Paulo: Fundação Getúlio Vargas, 2003. p. 107-134.

COSTA, L. D. The political economy of state provided health insurance in a progressive era: evidence from California. NBER Working Paper, n. 5328, 1995.

CUTLER, D. M.; GRUBER, J. The effects of medical expansions on public insurance, private insurance and redistribution. American Economic Review, v. 86, n. 2, 1996.

DIAMOND, P. Organizing the health insurance market. Econometrica, v. 60, n. 6, p. 1233-1253, 1992.

FARIAS, L. O.; MELAMED, C. Segmentação de mercados na assistência à saúde. Rio de Janeiro: Escola Nacional de Saúde Pública, Fiocruz, 2003. 
GETZEN, T. E. Health economics: fundamentals and flow of funds. New York: John Wiley \& Sons, Inc., 1997.

GIAMBIAGI, F.; ALÉM, A. C. Finanças públicas - Teoria e prática no Brasil. 2. ed. Editora Campus, s.d.

HOEL, A.; SÆTHER, M. R. Public health care with waiting time: the role of supplementary private health care. Journal of Health Economics, 841, p. 1-18, 2003.

JOHNSTON, J.; DINARDO, J. Econometric methods. McGraw-Hill International Editions, 1997.

JONES, A. M. Healthy econometrics. In: CULYER, A. J.; NEWHOUSE, J. P. Handbook of health economics. North-Holland, 2000. v. 1A.

NISHIJIMA, M.; BIASOTO JÚNIOR, G. O padrão de financiamento da saúde nos países da América. In: ENANPAD, 29, Brasília, 2005. Anais...

PAULY, M. V. The economics of moral Hazard: comment. Economic Review, v. 58, 1968.

REIS, O. M. L. S. O ressarcimento ao SUS pelas operadoras de planos de saúde: uma abordagem acerca do fundamento jurídico da cobrança. Dissertação (Mestrado)Universidade Federal de Viçosa, 2005.

STRAUSS, J.; THOMAS, D. Health nutrition, and economic development. Journal of Economic Literature, 36, p. 766-817, 1998.

WOOLDBRIDGE, J. M. Econometric analysis of cross section and panel data. Massachusetts: The MIT Press, 2002. 